\title{
Naïve Realism and The Cognitive Penetrability of Perception
}

\section{Forthcoming in Analytic Philosophy}

\author{
Dan Cavedon-Taylor \\ University of Southampton \\ d.cavedon-taylor@soton.ac.uk
}

\begin{abstract}
Perceptual experience has representational content. My argument for this claim is an inference to the best explanation. The explanandum is cognitive penetration. In cognitive penetration, perceptual experiences are either causally influenced, or else are partially constituted, by mental states that are representational, including: mental imagery, beliefs, concepts and memories. If perceptual experiences have representational content, then there is a background condition for cognitive penetration that renders the phenomenon prima facie intelligible. Naïve realist or purely relational accounts of perception leave cognitive penetration less well-explained, even when formulated with so-called 'standpoints' or 'third relata.'
\end{abstract}

Keywords: cognitive penetration; high-level perception; imagination; naïve realism; representationalism

\section{Introduction}

Philosophers and psychologists increasingly recognise that there is significant interaction between seemingly distinct parts of the mind, with particular attention paid to interaction 
between its perceptual and non-perceptual parts. The view of perception as a discrete information system that merely feeds into belief from the bottom-up is outdated. More and more, we are invited to recognise that there exist various top-down influences on visual, auditory, tactual, olfactory and gustatory experiences. ${ }^{1}$ These influencing states are diverse. Here I focus on mental imagery, beliefs, concepts and memories, though one might also consider intentions ( $\mathrm{Wu}$ 2013) and desires (Stokes 2012). Here are some representative examples:

Having moved into a new apartment, you are in the process of deciding how to arrange your furniture. You look around the lounge and visualise the sofa, bookcase, dining table, etc. in different locations. You don't imagine the furniture in phenomenal space ('the mind's eye'). You mentally project the items around this very room. In doing so, you see this room to be a potential location for this or that piece of furniture.

Dinner Party

You are attending a dinner party at your boss's house. Halfway through the meal, she reveals that the meat she has served is pigeon. You believe pigeons to be diseased-ridden vermin. But since you were just discussing the possibility of a pay rise, you resign yourself to swallowing a few mouthfuls more. Believing the meat to be pigeon, it now tastes different than before: more

$1 \quad$ This attitude is exemplified in a slew of recent research by philosophers of perception; see, for instance, the papers in Bennett \& Hill (2014), Stokes et al. (2014) and Zeimbekis \& Raftopoulos (2015). 
slimy, sour and disagreeable.

Jeweller

Missing Laptop

As one might infer from the diversity of these examples, I will be working with a broad notion of cognitive penetration. Although visual imagery, beliefs, concepts and memories have all been claimed to facilitate cognitive penetration, some might prefer to restrict use of
Your rich aunt owns a chain of jewellery stores. On your day off, you agree to drive her to several of the stores so that she can inspect deliveries of gems. At each, she tells you at length about the different types of cut, pointing out marquise cuts, oval cuts, princess cuts, and so on. By the end of the day, you have become rather good at telling them apart by sight. Where before the gems looked to be an unordered mishmash of colour and shape, acquiring concepts for the different cuts of gems means that they now look to be marquise cut gems, oval cut gems, princess cut gems, and so on.

You are in your office, engrossed in writing a paper. Called away to a meeting, you dutifully attend, itching to get back to your work. The meeting ends and you make a bee-line back to your office. You swing open your office door, expecting, from memory, your laptop to be where you left it. But it's not there! You see your laptop is gone. You don't merely see the presence of the wooden desk on which it sat, you are visually stunned by the laptop's absence. 
the term to cases such as Dinner Party. (The hallmarks of this case, and those like it, include an effect on perceptual experience that is synchronic with the forming of an occurent belief about the perceptual stimuli.) No matter. Dinner Party, and cases like it, will feature centrally here.

Another sense in which my understanding of cognitive penetration might be slightly unorthodox is that cognitive penetration is typically discussed in causal terms. In cognitive penetration, cognitive states are said to influence perceptual experiences and their phenomenology, or produce top-down effects upon such states. Indeed, definitions of cognitive penetration standardly build causation into them (see Stokes 2013 for an overview) and may understand cognitive penetration as involving fairly indirect mechanisms (Macpherson 2012). I have no qualms with thinking about some cases of cognitive penetration in this manner. But I do not think it is helpful to understand all cases of cognitive penetration in this way. It vastly understates just how entwined cognition and perception may become in cognitive penetration to say that one produces a causal influence on the other. Indeed, as some of the above examples illustrate, the penetrating cognitive state sometimes does more than merely influence the perceptual experience and its phenomenology, but would appear to partially constitute it. Just what this means will hopefully become clear in the paragraphs that immediately follow. If one finds it objectionable to call all such phenomena cognitive penetration, one could instead read me as discussing some broader phenomenon and give it a different label, e.g., 'top-down perceptual integration.' Let us examine the examples more closely.

In Arranging Furniture, your perceptual experience of the room is cognitively penetrated by mental images of furniture. You see the room. You visualise some furniture. But these 
states are not unrelated. You visualise the furniture to be located in the very room you currently see, undergoing a hybrid visual-imaginative state sometimes called 'makeperceive.' (Briscoe 2008; forthcoming) While your seeing the room per se is not constituted by any visual imagery, your seeing the room to be a potential location for, e.g., a bookcase, is partially constituted by your visualisation, and mental projection, of a bookcase into the room. Your seeing the room to be that way is not a mere causal effect of this mental act of projection, but is inseparable from it.

In Dinner Party, your gustatory experience of meat is cognitively penetrated by your belief about what kind of meat you are eating, but in a way that is causal rather than constitutive. You don't undergo a hybrid gustatory-belief state; rather, your belief that you are eating pigeon causally impacts your gustatory experience and its phenomenology. Your gustatory experience is thus cognitively penetrated in a synchronic manner by an occurently formed belief that you are eating pigeon. ${ }^{2}$

In Jeweller, your visual experience of gems alters due to the acquiring of concepts for each of the types of cut you have seen. You end up with an ability to visually distinguish the different types of cut, having gained throughout the day a disposition to recognise each type of cut by sight. You undergo what might be called diachronic cognitive penetration. Whether this is a case in which your visual experience of the gems, i.e. how they look to you, comes to be partially constituted by your newly-acquired concepts, or is merely causally influenced by them, is not clear.

2 Dinner Party is not without empirical precedent. There is experimental evidence that influencing people's beliefs about the origin of a sample of meat affects how sour it then tastes (Anderson \& Barrett 2016). 
In Missing Laptop, your visual experience of the laptop's absence is due to the cognitive penetration of perception by memory. An image of your laptop in working memory is subpersonally matched against incoming perceptual stimulus, e.g., of the table. The matching task fails since the laptop is not present. A perceptual experience of the laptop's absence ensues (Farennikova 2013). This has been claimed to be an indirect case of cognitive penetration (Farennikova 2015), suggesting it is causal, rather than constitutive. Here is another example of memorial-perceptual cognitive penetration, ${ }^{3}$ one that is perhaps less controversial and which involves memory partially constituting a perceptual experience and its phenomenology: tactually experiencing an object's 3-D shape in virtue of your memory unifying your temporally extended hand-movements over that object's surface.

I shall be arguing that cognitive penetration gives us reason to think that perceptual experiences have representational content. However, it is beyond the scope of this paper to defend cognitive penetration from its critics (see Fodor 1988; Pylyshyn 1999; Raftopoulos 2009; Deroy 2013; Machery 2015; Firestone \& Scholl 2016). Likewise, it is beyond this paper's scope to defend each of the above types of cognitive penetration. Therefore, I will be arguing for the conditional that if one is attracted to a view of perception on which it may be cognitively penetrated in the above sorts of ways, either causally or constitutively, then one has reason to think that perceptual experiences have representational content. As a corollary, one also has reason to reject, or at least modify, purely relational views of perception, like standard varieties of naïve realism, on which perceptual experiences are said not to involve representational content as part of their fundamental nature. ${ }^{4}$

3 The example is borrowed from borrowed from Matthew Fulkerson (2014: 60), though Fulkerson does not explicitly analyse it as a case of cognitive penetration.

$4 \quad$ One should also reject purely sensational views, like adverbialism. In what follows, I ignore such theories of perception. 
In section II, I lay out the distinction between representationalism and naïve realism. In section III, I argue that representationalism provides a framework within which cognitive penetration is made prima facie intelligible. In section IV, I distinguish two versions of naïve realism: dyadic naïve realism, on which perception is a relation between subject and object, and polyadic naïve realism, on which perception also includes so-called 'standpoint conditions' or 'third relata.' I then argue that neither has the resources to explain much about cognitive penetration. In section $\mathrm{V}$, I reject what I take to be the most promising response that naïve realists can give to this challenge: rethink the cognitive penetrability of perception as a more mundane case of cognitive-to-cognitive penetration. Section VI concludes with clarifying remarks.

\section{Representationalist and Naïve Realist Theories of Perception}

Two views on the nature of perceptual experiences are currently popular. According to representationalists, perceptual experiences are roughly akin to beliefs insofar as they represent the world as being some way (Dretske 1995; Lycan 1996; Tye 1995; Byrne 2009; Pautz 2010; Siegel 2010; Nanay 2015). For example, in believing Nathan to be tall, you are in a state that represents Nathan as being tall. Beliefs attribute properties. Your belief that Nathan is tall attributes to Nathan the property 'tallness' and in that respect your belief has content. In having content, beliefs can be accurate or inaccurate. Such is the nature of a representation. ${ }^{5}$ Think of a sketch, a map or a newspaper report. These all represent, and in doing so can misrepresent. Representations misrepresent when they misattribute properties. If Nathan is short, then your belief that he is tall, along with the sketch that you draw of him on

5 I restrict focus here to representations with so-called 'mind to world' direction of fit. 
the basis of that belief, misrepresent him; they both attribute to him a property, 'being tall', that he doesn't in fact posses.

Representationalists find it natural to extend this thinking to perceptual experiences. On their view, perceptual experiences also represent the world as being some way and so can be assessed for accuracy. In particular, in the case of veridical perceptual experiences, there is a fact of match between perceptual experience and world. Representationalists take it that this way of talking is only accounted for if perceptual experiences have representational content, and so are states whose nature is to report on what the mind-independent world is like. Consider the following remarks by Bence Nanay:

Many of our mental states are representations: my belief that it is raining outside represents a putative state of affairs: that it is raining outside. If I am afraid of a tiger, this fear is also directed at, or is about, something: a tiger. In other words, many mental states refer to something, they are about something: they have content. But then it is tempting to assume that perceptual states are also representations: they also have content: if I see a cat, it would be natural to say that my perceptual state is about this cat. (2015: 153-154)

Consider how this thinking extends to non-veridical perceptual experiences. For instance, suppose that there is a white swan before you. In low-level lighting conditions the swan may look black. The representationalist holds that it is intuitive to think of your visual experience now as inaccurate; that is, as misreporting on the colour properties of the swan insofar as the swan is white, not black. In hallucinating a white swan your perceptual experience is even 
more in error: it wrongly represents the presence of an object that is absent. On standard varieties of representationalism, whether you veridically see a white swan, are under an illusion of there being a while swan, or are hallucinating one, there is a common mental state present which types these situations as fundamentally the same, and which may be exploited to explain their indistinguishability (Pautz 2010); in all three, you are in a situation in which you perceptually represent there to be a white swan before you. The difference between the experiences is merely a difference in how you are caused to token that experience: via the actual presence of a white swan in the veridical case versus a different causal story in the case of non-veridical experiences, e.g., direct stimulation of the visual cortices in the case of hallucination.

When it comes to explaining perception's phenomenal character, representationalists appeal to representational content; that is, the sum total of properties represented by the experience. For instance, why does seeing a red tomato differ, experientially, from seeing a yellow lemon? The representationalist's answer is that the first represents such properties as, e.g., 'redness' and 'roundness', etc. In the second, it represents a different set of properties, e.g., 'yellowness' and 'ovoidness', etc. Granted, there are many significant dimensions along which representationalists disagree, a wholly uniform characterisation of the position is unnecessary for my purposes. ${ }^{6}$

\footnotetext{
6 Representationalists disagree over whether to identify the phenomenal character of perception with its representational content (strong/pure representationalism), or whether there is instead some relation between the two which is weaker than identity: mere supervenience, say (weak/impure representationalism). A view closely related to it agrees that perceptual experiences are representational mental states, but not exhaustively since perception's representational content suffices to determine its phenomenal character. Instead, defenders of the latter view invoke qualia, understood as purely sensational, nonrepresentational properties, in order to explain this aspect of perception (Peacocke 1983; Block 1996).
} 
The naïve realist rejects the above picture (Campbell 2002; Martin 2004; Travis 2004; Fish 2009; Antony 2011; Brewer 2011; Kalderon 2011; Logue 2012). In particular, they deny the twofold analogy between perception and belief affirmed by the representationalist. First, perceptual experiences, as the naïve realist understands them, do not have representational contents as part of their fundamental nature. Second, perceptual experiences are not mental states that, like beliefs, can be conceptually cleaved from their objects. Whereas representationalists understand perceptual experiences to be purely psychic states that are distinct from their objects, albeit caused by them when veridical and potentially present in those objects' absence, the naïve realist holds that perceptual experiences are constituted by such objects and so are relations between subjects and the mind-independent world. Thus, on naïve realism, the visual experience that you currently enjoy is not something which can be understood apart from the objects in the scene before you, and is partly made up by them.

This means that, for the naïve realist, the connection between perceptual experience and world is much tighter than on representationalism. This is claimed by naïve realists to be mirrored in perceptual phenomenology: in seeing the scene before you, you are seemingly not able to introspect your perceptual experiences as items that are distinct from, yet causally connected to, the objects in the scene before you; rather, all that is present to consciousness is the world itself. This is then taken to vindicate the naïve realist's account of the structure of perception insofar as their view is precisely that in perception the subject and the world form a relational unity (Snowdon 1990; Martin 2002b; Kennedy 2009). ${ }^{7}$ This means that whatever mental state you are in when you hallucinate, that state is not a perceptual experience, since it

7 Though see Soteriou (2013: ch5) for a naïve realist who denies that perception is wholly transparent in this manner. 
is in the nature of a perceptual experience to relate a subject to their environment and that, by definition, does not occur in hallucination. ${ }^{8}$

Some names for the world-involving relation at the heart of naïve realism include 'acquaintance', 'detection', 'a taking in', 'presentation', 'sensory awareness', and more besides. Notice that perceptual experiences themselves have no propositional or semantic structure, on this view. For relations hold or they do not. They are not the sorts of things that be true or false, accurate or inaccurate. If perception can be said to be structured at all, on naïve realism, then its structure is simply the worldly objects perceived, or perhaps those objects plus features of the perceiving subject. (This is a key matter that I return to in IV.)

How does a theory like this account for the phenomenal character of perception? It appeals to the worldly objects perceived. Here is an oft-quoted remark by John Campbell:

$[\mathrm{T}]$ he phenomenal character of your experience, as you look around the room, is constituted by the actual layout of the room itself: which particular objects are there, their intrinsic properties, such as color and shape, and how they are arranged in relation to one another and to you. (2002: 116)

Whereas the representationalist holds that seeing a tomato differs in phenomenal character from seeing a lemon due to differences in represented properties, e.g., redness and roundness

8 What the naïve realist should say about illusion is an even more complex affair. A selection of options includes: (i) typing illusions with hallucinations as fundamentally different in nature from veridical perceptions (Martin 2004); (ii) typing illusions with veridical perception and so collapsing the veridical/illusory distinction as standardly understood (Travis 2004; Antony 2011; Brewer 2011; Kalderon 2011); or (iii) holding a mixed view (Fish 2009). 
versus yellowness and ovoidity, the naïve realist's explanation is the two differ by virtue of the subject being related in each to different particular objects, each instantiating differing properties. Following Campbell's quote, the naïve realist holds that the perceiving of a tomato has the phenomenal character that it does because of facts about the tomato, its properties, rather than because of purely psychic facts about the perceiver. (Again, this is a somewhat delicate matter to which I return in IV.)

Having outlined what I take the disagreement between naïve realism and representationalism to fundamentally consist in, let us see what account each can give of cognitive penetration. ${ }^{9}$

\section{Cognitive Penetration and Representational Content}

Here are our earlier-discussed cases of cognitive penetration:

- Make-perceive: the partial constitution of a perceptual experience by mental imagery.

- The synchronic cognitive penetration of a perceptual experience via the causal influence of an occurently formed belief.

- The diachronic cognitive penetration of a perceptual experience via the causal influence of, or partial constitution by, concepts.

\footnotetext{
9 Needless to say, the differences between representationalism and naïve realism that I focus on here are not always adhered to. Some affirm a hybrid view on which perception is both relational and representational; I return to these theories, briefly, in the conclusion. What's more, some ways of understanding perceptual content render it relational (Burge 1991; Schellenberg 2011). In addition, some of those who think of perceptual experiences in representational terms are not happy with the suggestion that this makes such states belieflike, since they deny that perception is a propositional attitude (Crane 2009).
} 
- Absence perception: a perceptual experience of an object's absence that causally arises from, or is partially constituted by, a failure of match between working memory and perceptual stimuli.

In cognitive penetration, as I understand it, a non-perceptual state causally influences, or partially constitutes, a perceptual experience. What is more, the non-perceptual state is one with representational content (or, in the case of concepts, can be thought of as an element of such states, beliefs in particular). Let us examine make-perceive, cognitive penetration and absence perception in greater detail. I leave discussion of what I call here 'diachronic cognitive penetration' for the following section on naïve realism, since it is a case of cognitive penetration that at least two naïve realists have discussed and take themselves able to explain. It will be my aim to show that they fail to do so.

\section{III.i-Make-Perceive}

Consider the mental act of visualising a bookcase. This act can be understood in either one of two ways. First, one can understand the act in terms of the tokening of an image of a bookcase in purely phenomenal space, 'the mind's eye', as when day-dreaming. Alternatively, one can understand the act in terms of the tokening of an image which is represented as being located in one's actual egocentric space. For instance, one may visualise a bookcase as being in the corner of this very room, say, as in Arranging Furniture.

It is this second way of tokening the image that I want to focus on. It may be $a$ bookcase one imagines, i.e. no particular bookcase. Alternatively, one may visualise one's own bookcase, i.e. a particular object. Either way, the visual image of a bookcase is a state with content. Consider the case of visualizing a particular bookcase. Here, a particular object is represented 
by imagination as as being some way, e.g., as having a certain size, shape and perhaps colour. The visual image can be accurate or inaccurate. Maybe you 'mis-image' the height of your bookcase when visualising it to be in the corner of the room, only noticing the error when attempting to move it to that location. Alternatively, you might 'image' the bookcase correctly, bringing about a fact of match between the image and its object.

Above I said that one's seeing this room to be a potential location for a bookcase is partially constituted by the projecting of a mental image of the bookcase into the room. But the relationship between the image of the bookcase and one's (plain vanilla) visual experience of the room is so tight that, in this case at least, the explanatory relation seems to run in the other direction as well. For, just as part of what it is to see this room as a potential location for a bookcase is for one to mentally project into the room an image of the bookcase, what projecting the image into the room seems to first depend upon is one's (plain vanilla) seeing the room. Without mentally projecting the bookcase, one couldn't see the room in the way being described. But without first seeing the room (in the plain vanilla sense), one could not obviously be said to project the bookcase out into egocentric space.

If visual experience has representational content, then this case of cognitive penetration is made prima facie intelligible. The partial constitution of one's visual experience of the room as a location for a bookcase by mental imagery can be explained, at least in part, by both one's (plain vanilla) visual experience of the room and one's mental image of the bookcase being representational mental states; that is, in terms of both states having the same format. Clearly, to give a full account of this integration one would need to say a great deal about the mental activity involved in projecting the image into egocentric space. Crucially, however, understanding both states to be representations supplies a framework within which to develop 
that account, since understanding both states to be representations renders their constitutive integration minimally comprehensible. That is, it goes some way to explaining how it is possible for one to token an image of a bookcase within (plain vanilla) visual experience, so that it becomes a visual experience of the room as a potential location for a bookcase, to be told that the image and the (plain vanilla) visual experience are mental states of the same fundamental nature. In this episode of make-perceive, one's (plain vanilla) seeing of the room comes to be about not just the room, but also the bookcase. It is natural to say that the transformation is, in part, a matter of visual experience acquiring an additional content from the content the mental image.

\section{III.ii-Synchronic Cognitive Penetration}

Beliefs, as already noted, are paradigm examples of representational mental states. Your belief in Dinner Party that you are eating pigeon is a state that represents the world as being some way; in particular, it represents the meat that you are eating as being pigeon. The state can be accurate or inaccurate. If your boss was joking when she asserted that the meat is pigeon, then your belief is inaccurate. It gets wrong a certain fact about the world; or, more precisely, a certain fact about what is in your mouth.

If your gustatory experience of the meat is also one with representational content-if it represents the meat as being some way-we thereby make it prima facie intelligible how the content of your belief about the meat can have a direct causal impact upon your perceptual experience of the meat: the former has that impact because its representational content affects the latter's representational content. Again, a shared representational framework across perception and belief offers a minimally explanatory framework that, while falling short of 
accounting for all the details of cognitive penetration, begins to make intelligible how a belief can causally influence a perceptual experience.

A related idea has been defended by Zenon Pylyshyn, who first coined the term 'cognitive penetration.' Pylyshyn argues that cognitive penetration requires that beliefs have a "semantically coherent" (1999: 343) influence upon perception on the basis that causal influence is insufficient. While this idea has not gone unchallenged (Stokes 2013), it has been robustly defended by Fiona Macpherson (2012: 26; 2017: 9-10), and is often claimed to be partially definitive of the phenomenon (Wu 2013; Brogaard \& Gatzia 2015; Lupyan 2015a; Teng 2016; Gross 2017; Burnston forthcoming; Fridland forthcoming). In particular, Macpherson argues that the semantic coherence condition can help distinguish cases of cognitive penetration from cases like the following:

Important Exam

You wake up believing that today is the day of an important exam. This belief causes you to get stressed out and anxious, thereby bringing on a migraine. The migraine involves various disturbances in your visual field; you experience strobing lights in the periphery of your vision.

Intuitively, Important Exam differs from Dinner Party in its not being a case of cognitive penetration. Although it is an example of a belief causally influencing a perceptual experience, examples of such influences are rife and do not automatically count as cognitive penetration. (For instance, believing that the person in front of you at the supermarket checkout is your favourite musician, you might look at them for longer than you would otherwise.) 
As Macpherson points out, if there is a semantic coherence condition on cognitive penetration, then we can easily explain why Important Exam fails to be a case of cognitive penetration: namely, that unlike in Dinner Party, there is no intelligible connection between the content of your belief and the change that it brings about to your visual experience. Although we know that believing a stressful event to be impending can cause migraines and visual disturbances, there is nothing here that makes these changes to your vision intelligible in the sense of its being rational or reasonable for your visual experience to be that way in light of your migraine. Contrast this with Dinner Party. It seems quite reasonable that you would experience the food in your mouth to be slimier and sourer than before, upon coming to believe that you are eating pigeon, coupled with your background belief that pigeon are disease-ridden vermin.

I said above that the semantic coherence condition on cognitive penetration is related to my suggestion that synchronic cognitive penetration is made intelligible by both the penetrating belief and penetrated perceptual experience being states with representational content. How, precisely, are the two claims related? The answer is simple: one can explain, in part, what the semantic coherence condition amounts to if one assumes that both perceptual experiences and beliefs are states with representational content. In effect, the semantic coherence condition on cognitive penetration may be understood as having this as a prior condition: that the penetrating and penetrated states have representational content. Consider, in this regard, Steven Gross's comments on semantic coherence:

A central feature of propositional attitudes is that they do directly affect one another in semantically coherent ways. Indeed, their availability for rational inference about 
what to believe and what to do-and the conceptual structure this imposes upon them-is among their most important functional features. If perceptual states... interacted with propositional attitudes in a similar way, this would be a strong argument for a crucial continuity with them. (2017: np)

The so-called 'continuity' between perception and cognition that cognitive penetration is often taken to motivate is the very strong one that the very distinction between perception and cognition may collapse (Shea 2014; Lupyan 2015b). The continuity between perception and cognition that I am motivating here as a partial explanation of synchronic cognitive penetration (via its explaining, in part, what semantic coherence amounts to) is a much weaker one. However, it significance for our understanding the fundamental nature of perception is far from insignificant, since it is that both are representational mental states, i.e. have semantic content.

\section{$\underline{\text { III.iii-Absence Perception }}$}

Perhaps the most controversial case of cognitive penetration that I focus on here is absence perception: seeing (or hearing, or smelling, or feeling, or tasting) an object to be missing. In Missing Laptop you see your laptop to be missing. If we accept that such perceptual experiences are possible, we will want to know how they are possible. A plausible 'expectational mechanism' that explains at least some such experiences is memoryperception mismatching (Farennikova 2013; 2015). ${ }^{10}$ First, an image (or object-template), which encodes visual properties of an object, $\mathrm{O}$, is tokened in working memory via the registering of contextual, environmental cues. Once tokened, the template is projected in

10 This mechanism may not explain all cases of absence perception. See Martin \& Dokic (2013), Roberts (2016) and Cavedon-Taylor (2017) for some alternatives. 
order to be matched against further incoming perceptual stimuli. Such projecting is described as "a process of holding up the template of a searched object for the purpose of comparison of its perceptual attributes with the attributes of the perceived scene." (2013: 441) If there is a mismatch, i.e. if the projected template of $\mathrm{O}$ fails to refer to any object in the perceived scene, the result is that $\mathrm{O}$, e.g., the laptop, is seen to be absent.

If perceptual experiences have representational content, then there is a framework within which to account for the matching that goes on in absence perception and which, crucially, explains why the failure of the matching task results in a perceptual experience of absence. The object-template of the laptop that is tokened in working memory is a state with representational content. It represents your laptop. If the visual experience you have of the surface of the desk is one with representational content, then we can make sense of the possibility of a failure of match between the two in terms of a failure of match in content. Unless the memory state were of broadly the same nature as the visual experience, one might think that we would not be able to explain why the failure of match should result in a perceptual experience of something's being missing. Indeed, without the two being representations, one might think that talk of 'matching' and 'non-matching' wouldn't make sense.

I want to stress at this point that none of the above shows that a shared representational framework across cognition and perception is sufficient for explaining cognitive penetration. Indeed, that sufficiency claim is false. Your current perceptual experience is unlikely to be penetrated, either causally or constitutively, by your beliefs about, e.g., basic arithmetic, what day today is, or that Cairo is the capital city of Egypt, etc. At most, what I've said above supplies reason to believe that a shared representational framework is one (of no doubt many) 
background necessary conditions for cognitive penetration. Still, it would be a highly significant one, since we have seen that this is not the naïve realist's account of the fundamental nature of perception. It is also worth stressing that the claims offered so far do not (at least yet) even establish this necessity claim. Since, for all I have said, the naïve realist framework may supply an account that similarly explains important aspects of cognitive penetration, and that account may even be preferable to one that invokes perceptual representations. It is to their account that I now turn.

\section{Cognitive Penetration Without Perceptual Representation?}

In section II, I characterised naïve realism as the thesis that perceptual experience is a relation between a subject and mind-independent object. With that in mind, let us consider the following formulation of the view:

Dyadic naïve realism: S's perceptual experience of the scene before them is exhaustively constituted by the particular objects and property instances of which that scene is comprised.

Although I use the term 'dyadic' here, it is important to be clear that the view explains the nature and phenomenal character of perceptual experiences by reference to only one constituent of the relation: the object of perception. (The rationale for calling the view 'dyadic' will emerge shortly, given Campbell's (2009) view reproduced below.) Naïve realism is commonly glossed in just this way, with the perceived object doing the heavylifting. Recall Campbell’s (2002) remark: “[T]he phenomenal character of your experience, as you look around the room, is constituted by the actual layout of the room itself." Consider as well how Tim Crane and Craig French introduce the view in a survey article: 
Take the churchyard covered in white snow and suppose one sees this for what it is. Why is this a case of things appearing white to one? Here the naive realist appeals to the real presence in the experience of the white snow itself. The character of one's experience is explained by an actual instance of whiteness manifesting itself in experience. (2017: np, emphasis my own)

But dyadic naïve realism is arguably too naïve (as Crane \& French and Campbell recognise). Indeed, Campbell (2009: 657-659) has more recently suggested that a full characterisation of the structure and phenomenology of a subject's perceptual experience must include a number of further elements. Campbell calls the total ensemble of such elements a 'standpoint' or 'point of view.' It includes:

- The sense modality used to perceive.

- The particular place in which the perceiving occurs.

- The particular time at which the perceiving occurs.

- The subject's distance from the perceived object.

- The relative orientations of the subject and/or object.

- The temporal dynamics of the experience, including movement of the object or perceiver.

Campbell thus writes: 
We should think of [perceptual] consciousness of the object not as a two-place relation between a person and an object, but as a three-place relation between a person, a standpoint and an object. You always experience an object from a standpoint. And you can experience one and the same object from different standpoints. (2009: 657, emphasis my own)

With these extra factors now introduced, let us define, in a highly schematic way, a different version of naïve realism:

Polyadic naïve

realism:
S's perceptual experience of the scene before them is exhaustively constituted by the particulars and property instances of which that scene is comprised, as well as further, relevant relata.

I have deliberately left underspecified the standpoint conditions. One reason for doing so is that different naïve realists may wish to formulate the view with different relata. For example, polyadic naïve realism is affirmed by both Bill Brewer (2011) and William Fish (2009), though the latter does not explicitly talk in terms of standpoints. While Brewer's formulation is exceptionally close to Campbell's, ${ }^{11}$ Fish's focus is on such things as visual acuity (Ibid:

11 One difference is that Brewer's view has it that the standpoint conditions play something of an additive role, in part explaining the instantiation of sensible properties. On Campbell's view, they play a sectional role, making revealed certain prior instantiations (see French (2014) for an insightful discussion, but then see fn11 below). Moreover, Campbell's view, but not Brewer's, is couched in Fregean terms. One might also see Johnston (2004) as having an additive account of standpoints since Johnston believes that in illusion (and hallucination) one comes to be perceptually related to properties, albeit uninstantiated ones; presumably Johnston would think that this can happen as a result of one's cognitive states. 
55-56) and attention (Ibid: 64). For example, what it is like for Nathan to see a white swan is determined not only by the swan itself, his spatial relation to it, his visual acuity, and so on, but also how he distributes his attention over the animal. Fish's solution to this potential difficulty is to factor attention into perception by considering it too to be part of the standpoint conditions (see also Brewer 2013). ${ }^{12}$

Taking stock, it appears that the polyadic naïve realist can employ a simple two-step strategy in order to explain seemingly troublesome variations in perceptual phenomenal character, whether between different subjects perceiving the same object at the same time or between the same subject perceiving the same object at different times:

Step one: isolate the factor that is responsible for the variation in phenomenal character, e.g., visual acuity, attention, etc.

Step two: $\quad$ include that factor as part of the standpoint/third relatum.

12 One might wonder whether this concept of a 'standpoint' is in good order. In particular, there is significant ambiguity about whether it is an object of perception or a background, shaping condition of that relation (whether playing an additive or selectional function). Going by Campbell's list, standpoint conditions include such things as the subject's distance from the perceived object and the orientation of that object. These are naturally taken to fall on the side of what is perceived rather than on the side of the newlyintroduced relatum, i.e. the standpoint, whose intended role is to modify how the object is perceived (Campbell 2014: 51). French's (2014: 400) characterisation of Campbell's standpoint as selectional is thus not wholly accurate. It would be more accurate to say that standpoints, on Campbell's view, play both a selectional and presentational role in perception, whether or not Campbell recognises it. Moreover, many of these standpoint factors, e.g., the sense modality used, may already be accounted for by a two-place conception of perceptual experiences that gives equal, or near-equal, weight to both relata (see Logue 2012; Soteriou 2013: ch5). For the sake of argument, I will assume that these ambiguities can be overcome via a more perspicuous account of the inter-relations of the relevant relata (but see Cassam 2014 for further worries). 
Now let us consider what dyadic and polyadic naïve realism have to say about cognitive penetration. $^{13}$

First, it is clear that dyadic naïve realism leaves no room for, and is seemingly inconsistent with, cognitive penetration. In cognitive penetration, the phenomenal character of perceptual experience is altered without a corresponding alteration to the object of perception. For instance, in Dinner Party, what it is like for you to taste the food in your mouth, prior to forming the belief that it is pigeon you are eating, differs from what it is like for you to taste that same food while affirming this belief. Cognitive penetration is not accommodated by this view since it affirms that perception's phenomenal character is exhaustively characterised by external objects and their properties. This leaves no room for anything else, like mental imagery, beliefs, concepts or memories, to affect perception's phenomenal character (compare Block 2010: fn.8). Insofar as one thinks that there are such cases of cognitive penetration, one should prefer representationalism. For representationalism, we have seen, is not merely consistent with cognitive penetration, it provides a framework that begins to make comprehensible various types of the phenomenon.

By contrast, it appears that polyadic naïve realism does provide a framework for accommodating cognitive penetration. In cognitive penetration, factors putatively external to perception alter its phenomenal character. That is precisely what the two-step strategy highlighted above is meant to aid the naïve realist in explaining. The standpoint, or thirdrelatum, can simply be further expanded to include mental imagery, beliefs, concepts,

13 There are other ways in which to cash out the distinction between dyadic and polyadic naïve realism. Block (2010) calls the former 'naïve realism' and the latter 'direct realism'. Mehta \& Ganson (2016) call dyadic naïve realism 'clean phenomenal particularism.' See Logue (2012) and French (2014) for others distinctions one can make between versions of the theory. 
memories, etc. so that what is putatively outside of perception becomes a part of it. Polyadic naïve realism, by its very nature, seems to make room for cognitive penetration: mental imagery, beliefs, concepts, memories, etc. can be folded into perception by their being elements that, along with attention, acuity, sense modality, etc., constitutively shape the nature and phenomenology of perceptual relations to external objects. As Brewer puts it, though not in relation to cognitive penetration per se: "experiential variations... may all perfectly adequately be accounted for by variations within this third relatum.” (2013: 424; 2011: 96)

But there is a problem here. Contrary to appearances, this two-step strategy says very little that is explanatory of how representational states may alter perceptual experiences, whether causally or constitutively. Polyadic naïve realists would seek to explain cognitive penetration in terms of the penetrating states being extra relata, over and above the objects in the scene, the subject's spatial relation to those objects, their visual acuity/attention, etc. The difficulty is that this merely stipulates, rather than explains, the alteration of a subject's perceptual experiences by their non-perceptual ones. Cognitive penetration, on this model, does not get illuminated in even the minimal sense that it does on representationalism; that is, by reference to the shared representational nature which can account for such things as, e.g., the semantic coherence condition on synchronic cognitive penetration (as in Dinner Party) and the fact of mis-match in cases of absence perception (as in Missing Laptop). Polyadic naïve realists who would invoke the two-step strategy in order to account for cognitive penetration end up, by all appearances, taking for granted, rather than explicating, the phenomenon.

In addition, given the naïve realist's account of the fundamental nature of perception, i.e. as a non-representational relation, the causal or constitutive integration of perceptual experiences 
with representational states is not something that they are at liberty to simply help themselves to. On the naïve realist's view, perceptual experiences have a nature that is crucially distinct from the nature of cognitive states: they are presentations or relations, not representations with content. This is part of the reason why attempting to cash out cognitive penetration in terms of standpoints and third relata fails to be something that itself explains, but which itself calls out for explanation. What one wants to know is: how do representational states of mind get to be part of the motley crew of standpoint conditions for non-representational perception? Polyadic naïve realism, is thus not only uninformative regarding the basic 'how' of cognitive penetration, it is uninformative in the face of significant pressure for some further explanation.

As an example of this problem, consider Fish's (2009) and Johnston's (2006) claims regarding the influence of concepts on perception, as in diachronic cases like Jeweller. Fish claims that the subject's concepts, no less than their visual acuity and attention, determine the nature and phenomenology of perceptual experiences. Both Fish and Johnston affirm that while low-level properties do not require corresponding concepts for their perception, highlevel ones, e.g., natural and artefactual kinds, are only perceived via concept-possession. Johnston writes:

Conceptual sophistication helps us to use our senses to mine the scene, or more generally the scenario before the senses, for relevant exemplifications-his bluffing, her raising, your having a busted straight. (2006: 283)

Similarly, Fish (2009: 70) claims that a subject has the capacity to "pick up" the property of a thing's being a shoe, a computer, etc. only if the subject has the concepts SHOE, COMPUTER, 
etc. What Fish has in mind is that acquiring these concepts alters one's perceptual experiences of shoes and computers such that one can perceive them as such, i.e. as shoes or as computers.

Yet the very thing the naïve realist needs to explain is what picking up or mining an object for a property, via concept possession, amounts to. What is problematic is not so much how to unpack these analogies. That is straightforward: concepts allow perceivers to be perceptually related to properties they would not be perceptually related to otherwise. The difficulty comes at an earlier step: explaining how the subject's conceptual repertoire gets integrated into perception to begin with. Conceiving of a subject's concepts as things that 'constitutively shape' their perceptual relations to objects, or which are 'aspects of the standpoint conditions', is not explanatory, but stands in need of explanation. In particular, it stands in need of explanation given the naïve realist's account of perception as non-representational. ${ }^{14}$

If what I have said here is right, then cognitive penetration favours representational content. Representational content does not, by itself, explains all facets of cognitive penetration. Rather, perception's having representational content provides an explanatory framework within which to develop the complete story about the causal, or constitutive, integration of representational states with perception that is definitive of the phenomenon. (This is perhaps clearest in the case of the semantic condition on synchronic cognitive penetration.) The suggestion is that representational content be thought of as a background necessary condition for cognitive penetration. It is certainly not the only such condition, but if what I have said

14 Berit Brogaard and Bartek Chomanski (2015: 481) also object to the naïve realist's inclusion of concepts in perception to explain high-level perception. They write "The idea that cognitive processes directly determine which property instances get picked out does not seem to be in the spirit of naïve realism." This objection is misplaced. At best, their remarks are true only of dyadic naïve realism. It precisely in keeping with the spirit of polyadic naïve realism to factor such elements into perceptual experience (see Brewer 2013: 424; 2011: 96). 
here is right, it is a significant one insofar as it provides an important lesson for the correct metaphysics of perception.

\section{Cognitive Penetration Rethought}

What might the naïve realist say in reply to this challenge? Perhaps the most promising reply would be to claim that cognitive penetration occurs not within perception itself, but is a matter of representational states causally, or constitutively, affecting the content of other representational states, ones that are closely-associated with perceptual experiences, but which are strictly post-perceptual. The shape of this proposal echoes a currently popular strategy that naïve realists have adopted for explaining perceptual illusions: the error is not in perception itself, since perception is mere passive presentation, but in the forming of certain contentful states from perception (Travis 2004; Antony 2011; Brewer 2011; Kalderon 2011). Here, what has been claimed to be a perceptual phenomenon is rethought in terms of a purely cognitive one. Likewise, the thought might go that one can say the same about cognitive penetration.

At best, this strategy will have mixed success. For instance, one should grant that cases of diachronic cognitive penetration, as in Jeweller, could coherently be understood to involve concepts affecting post-perceptual states, rather than perceptual ones (see Reiland 2014). However, it is instructive to note that this is not what is claimed by Johnston and Fish. The most natural reading of Johnston's claim that concepts affect the "use our senses to mine the scene, or more generally the scenario before the senses," (2006: 283) is that concepts integrate with perceptual experiences themselves. In the case of Fish (2009), it is clearer still that concepts are being said to affect perceptual experiences. Fish places concepts in the same boat at attention and visual acuity; that is, as factors that shape the nature and phenomenology 
of perceptual experiences, not anything post-perceptual. Put in Brewer's (2011) and Campbell's (2009) terms, Fish's view is straightforwardly that concepts are part of perception's third-relatum or standpoint conditions. Thus, both Johnston and Fish are to be read as attempting to explain high-level property perception within the naïve realist framework. So while the strategy of rethinking the cognitive penetrability of perception in purely cognitive terms may be coherent (at least for diachronic cases), it is not friendly to already-existing naïve realist accounts of the phenomenon.

Rethinking the cognitive penetrability of perception as a purely cognitive phenomenon fares less well for other types of cognitive penetration. Consider make-perceive, as in Arranging Furniture. Visualising the bookcase in this or that corner of the room is not happily understood to be a matter of combining an image of a bookcase with a contentful state formed post-perceptually. What the bookcase image is most naturally taken to integrate with is one's perceptual experience of the room itself. As discussed above, unless the bookcaseimage were to constitutively penetrate one's (plain vanilla) perceptual experience of the room, the very act of projecting the image into egocentric space becomes mysterious. And again, there are naïve realists who discuss this very phenomenon in terms that suggest they consider it to be a perceptual one (Martin 2002b: 140).

Finally, compare the case of cognitive penetration by memory mentioned at the beginning of this paper: tactually experiencing an object's 3-D shape in virtue of memory unifying your temporally extended hand-movements over that object's surface. If one interprets this, and similar examples, as cases that are purely intra-cognitive, then one risks being left with a very thin and uninteresting notion of tactual experience itself. Without concepts and memory being causally relevant for, or constitutively woven into, tactual experiences, sensory 
awareness in this modality becomes seemingly restricted to spatially and temporally disjoint points of contact between one's skin and an object's surface. One one will miss out on many ordinary tactual experiences that require memory in order to become temporally unified. Consider, e.g., tactually sensing there to be a flat surface before you via gliding your palm over it, tactually sensing the object in your pocket to be a ring via slipping a finger through it, or tactually sensing the curvature of your drinks glass via running your fingers down it. These temporally extended experiences are missing from a view on which memory cannot constitutively penetrate tactual perception itself.

So, at best there are only some cases of cognitive penetration that the strategy under consideration might explain. But doing so will leave cold many naïve realists who are already committed to various types of the phenomenon being bona fide perceptual.

\section{Conclusion}

I have claimed that those who favour a view of perception as subject to cognitive penetration by such representational states as, e.g., visual images, beliefs, concepts and memories, thereby have reason to think that perception also has representational content. Although it is natural to interpret this line of thinking as simply saying that cognitive penetration requires the truth of representationalism and the abandonment of naïve realism, that would be too quick. While one way to accommodate cognitive penetration would be to endorse representationalism, a number of philosophers have recently claimed that it is possible to affirm hybrid accounts of the nature of perception on which it is fundamentally both relational and representational (Bengson et al. 2011; Logue 2014; Cavedon-Taylor 2015). These impure forms of naïve realism or relationalism require further exploration, but they are not at all threatened by the arguments developed here. They aim to preserve central 
phenomenological and epistemic insights that the naïve realist's account of perception has to offer, e.g., in terms of explaining the phenomenal particularity of perception (Martin 2002a) and knowledge of reference (Campbell 2002), while having the additional explanatory benefits afforded by representational content. In this paper, I have outlined what seems to be one such benefit: a framework for explaining various aspects of cognitive penetration.

\section{Acknowledgements}

Thanks to past colleagues at the University of Antwerp for helpful feedback on this paper, especially Laura Gow and Bence Nanay. Thanks to Craig French for providing comments on an earlier version and to one of the journal's anonymous referees for comments on a more recent one. This paper was made possible by funding from...

\section{References}

Anderson, E. \& Barrett, L. (2016) "Affective Beliefs Influence the Experience of Eating Meat." PLoS ONE 11(8): e0160424. https://doi.org/10.1371/journal.pone.0160424

Antony, L. (2011). “The Openness of Illusions.” Philosophical Issues 21: 25-44.

Bengson, J., Grube, E. \& Korman, D. (2011). “A New Framework for Conceptualism.” Nous 45: 167-189.

Bennett, D. \& Hill, C. (eds.) (2014). Perceptual integration and the Unity of Consciousness. MIT Press.

Block, N. (1996). "Mental Paint and Mental Latex.” Philosophical Issues 7: 19-49.

Block, N. (2010). “Attention and Mental Paint.” Philosophical Issues 20: 23-63.

Brewer, B. (2011). Perception and Its Objects. OUP.

Brewer, B. (2013). "Attention and Direct Realism." Analytic Philosophy 54: 421-435.

Briscoe, R. (2008). "Vision, Action, and Make-Perceive." Mind \& Language 23: 457-497.

Briscoe, R. (forthcoming). "On the uses of Make-Perceive." In F. Macpherson \& F. Dorsch (eds.), Perceptual Memory and Perceptual Imagination. OUP.

Brogaard, B. \& Chomanski, B. (2015). "Cognitive Penetrability and High-Level Properties in Perception: Unrelated Phenomena?” Pacific Philosophical Quarterly 96: 469-486.

Brogaard, B. \& Gatzia, D. (2015). "Is the Auditory System Cognitively Penetrable?" Frontiers in Psychology 6. https://doi.org/10.3389/fpsyg.2015.01166

Burge, T. (1991). "Vision and Intentional Content." In E. Lepore and R. Van Gulick (eds.) John Searle and his Critics. CUP.

Burnston, D. (forthcoming). "Cognitive Penetration and the Cognition-Perception Interface." Synthese

Byrne, A. (2009). “Experience and Content.” Philosophical Quarterly 59: 429-451.

Campbell, J. (2002). Reference and Consciousness. OUP.

Campbell, J. (2009). “Consciousness and Reference.” In B. McLaughlin, A. Beckermann and S. Walter (eds.), Oxford Handbook to the Philosophy of Mind. OUP.

Campbell, J. (2014). "Experiencing Objects as Mind Independent." In J. Campbell and Q. Cassam, Berkeley's Puzzle: What Does Experience Teach Us? OUP.

Cassam, Q. (2014). "The Relational View of Experience.” In J. Campbell and Q. Cassam, Berkeley's Puzzle: What Does Experience Teach Us? OUP. 
Cavedon-Taylor, D. (2015). "Kind Properties and the Metaphysics of Perception: Towards Impure Relationalism.” Pacific Philosophical Quarterly 96: 487-509.

Cavedon-Taylor, D. (2017). "Touching Voids: On the Varieties of Absence Perception." Review of Philosophy and Psychology 8: 355-366.

Crane, T. (2009). "Is Perception a Propositional Attitude?" Philosophical Quarterly 59: 452469.

Crane, T. \& French, C. (2017). "The Problem of Perception." In Edward N. Zalta (ed.), The Stanford Encyclopedia of Philosophy (Spring 2017 Edition). https://plato.stanford.edu/archives/spr2017/entries/perception-problem

Deroy, O. (2013). 'Object-Sensitivity versus Cognitive Penetrability of Perception." Philosophical Studies 162: 87-107.

Dretske, F. (1995). Naturalizing the Mind. MIT Press.

Farennikova, A. (2013). "Seeing Absence.” Philosophical Studies 166: 429-454.

Farennikova, A. (2015). "Perception of Absence and Penetration from Expectation." Review of Philosophy and Psychology 6: 621-640.

Firestone, C. \& Scholl, B. (2016). "Cognition Does not Affect Perception: Evaluating the Evidence for "Top-Down" Effects." Behavioral and Brain Sciences 39: 1-72.

Fish, W. (2009). Perception, Hallucination, and Illusion. OUP.

Fodor, J. (1988). "A Reply to Churchland's 'Perceptual Plasticity and Theoretical Neutrality." Philosophy of Science 55: 188-198.

French, C. (2014). "Naïve Realist Perspectives on Seeing Blurrily." Ratio 27: 393-413.

Fridland, E. (forthcoming). "Automatically Minded." Synthese

Fulkerson, M. (2014). The First Sense: A Philosophical Study of Human Touch. MIT Press.

Gross, S. (2017). "Cognitive Penetration and Attention." Frontiers in Psychology 8. https://doi.org/10.3389/fpsyg.2017.00221

Johnston, M. (2004). "The Obscure Object of Hallucination." Philosophical Studies 120: 113-83.

Johnston, M. (2006). "Better Than Mere Knowledge? The Function of Sensory Awareness." In J. Hawthorne \& T. Gendler (eds.), Perceptual Experience. OUP.

Kalderon, M. (2011). “Color Illusion.” Nous 41: 751-775.

Kennedy, M. (2009). "Heirs of Nothing: The Implications of Transparency." Philosophy and Phenomenological Research 79: 574-604.

Logue, H. (2012). “Why Naïve Realism?” Proceedings of the Aristotelian Society 112: 211237.

Logue, H. (2014). "Experiential Content and Naive Realism: A Reconciliation." In B. Brogaard (ed.), Does Perception Have Content? OUP.

Lupyan, G. (2015a). "Cognitive Penetrability of Perception in the Age of Prediction: Predictive Systems are Penetrable Systems." Review of Philosophy and Psychology 6: 547-569.

Lupyan, G. (2015b). "Reply to Macpherson: Further illustrations of the cognitive penetrability of perception." Review of Philosophy and Psychology 6: 585-589.

Lycan, W. (1996). Consciousness and Experience. MIT Press.

Machery, E. (2015). “Cognitive Penetration: A No-Progress Report.” In A. Raftopoulos \& J. Zeimbekis (ed.), Cognitive Penetrability of Perception: New Philosophical Perspectives. OUP.

Macpherson, F. (2012). "Cognitive Penetration of Colour Experience: Rethinking the Issue in Light of an Indirect Mechanism." Philosophy and Phenomenological Research 84: 24-62.

Macpherson, F. (2017). "The Relationship Between Cognitive Penetration and Predictive Coding." Consciousness \& Cognition 47: 6-16. 
Martin, J-R. \& Dokic, J. (2013). "Seeing Absence or Absence of Seeing?" Thought: A Journal of Philosophy 2: 117-125.

Martin, M. (2002a). "Particular Thoughts \& Singular Thought." Royal Institute of Philosophy Supplement 51: 173-214.

Martin, M. (2002b). “The Transparency of Experience.” Mind \& Language 4: 376-425.

Martin, M. (2004). "The Limits of Self-Awareness.” Philosophical Studies 120: 37-89.

Mehta, N. \& Ganson, T. (2016). "On the Generality of Experience: A Reply to French and Gomes." Philosophical Studies 173: 3223-3229.

Nanay, B. (2015). "Perceptual Representation / Perceptual Content." In M. Matthen (ed.), Oxford Handbook for the Philosophy of Perception. OUP.

Pautz, A. (2010). "Why Explain Visual Experience in Terms of Content?” In B. Nanay (ed.), Perceiving the World. OUP.

Peacocke, C. (1983). Sense and Content. OUP.

Pylyshyn, Z. (1999). "Is Vision Continuous with Cognition? The Case for Cognitive Impenetrability of Visual Perception." Behavioral and Brain Sciences 22: 341-423.

Raftopoulos, A. (2009). Cognition and Perception: How Do Psychology and Neural Science Inform Philosophy? MIT Press.

Reiland, I. (2014). "On Experiencing High-Level Properties." American Philosophical Quarterly 51: 177-187.

Roberts, T. (2016). "A Breath of Fresh Air: Absence and the Structure of Olfactory Perception." Pacific Philosophical Quarterly 97: 400-420.

Schellenberg, S. (2011). "Perceptual Content Defended." Nous 45: 714-750.

Siegel, S. (2010). The Contents of Visual Experience. OUP.

Snowdon. P. (1990). “The Objects of Perceptual Experience." Proceedings of the Aristotelian Society 64: 121-50.

Soteriou, M. (2013). The Mind's Construction. OUP.

Stokes, D. (2012). "Perceiving and Desiring: A New Look at the Cognitive Penetrability of Experience." Philosophical Studies 158 :479-92.

Stokes, D. (2013). "Cognitive Penetrability of Perception." Philosophy Compass 8: 646-663.

Stokes, D., Matthen, M. \& Biggs, S. (eds.) (2014). Perception and its Modalities. OUP.

Teng, L. (2016). "Cognitive Penetration, Imagining, and the Downgrade Thesis." Philosophical Topics 44: 405-426.

Travis, C. (2004). "The Silence of the Senses." Mind 113: 57-94.

Tye, M. (1995). Ten Problems of Consciousness. MIT Press.

Wu, W. (2013). Visual Spatial Constancy and Modularity: Does Intention Penetrate Vision? Philosophical Studies 165: 647-669.

Zeimbekis, J. \& Raftopoulos, A. (eds.) (2015). The Cognitive Penetrability of Perception: New Philosophical Perspectives. OUP. 